\title{
A Promoção das Relações entre a Universidade e o Município: desafios do programa de extensão UERJ Teresópolis Construindo Vínculos
}

Promotion of Relations between the University and the City: The Challenges of the Extension

Program Uerj Teresópolis Building Links

Autor

Leandro Souza Moura. Professor do Instituto de Geografia, Departamento de Turismo da Universidade do Estado do Rio de Janeiro (UERJ).

E-mail: leandro.moura@ueri.br

Recebido em: 24/08/2016 Aprovado em: 16/01/2018

DOI: $10.12957 /$ interag. 2017.25218

\section{Relato}

Entende-se que a relação com a comunidade em que está inserida é primordial nos programas de extensão, e é ponto de partida para o projeto construindo vínculos, visto que seu principal objetivo é estreitar as relações entre a universidade e o município de Teresópolis uma vez que, apesar de estar na cidade desde 2010, ainda há muitos teresopolitanos que desconhecem a presença da Universidade do estado do Rio de Janeiro (UERJ) na sua cidade. Desde o início o Projeto vem atuando com ações pedagógicas e sociais e, com o tempo, vem buscando diversificar tais atividades. Os programas de extensão cumprem um papel de fortalecimento das raízes da universidade, não permitindo que ela se distancie dos problemas vividos pelos cidadãos em seu entorno ao mesmo tempo em que mostra sua relevância na
Abstract

It is understood that the relationship with the community in which it operates is paramount in extension programs, and it is the starting point for the Building Ties Project since its main objective is to strengthen relations between the University and the city of Teresópolis. Despite the fact that UERJ has been present in this city since 2010 there are still many people who are unaware of it. From the beginning, the project has been working with educational and social activities, and in time, it has been seeking to diversify these activities. Extension programs play a role in strengthening the University roots, not allowing it to move away from the problems faced by citizens in their surroundings while showing the relevance of these programs in the community where the University operates. Gradually the program 
vida da comunidade onde está inserida. Paulatinamente o programa vai abrindo frentes de trabalho, fazendo contatos, envolvendo pessoas e instituições que passam a conhecer a universidade e a se relacionar com ela. É um esforço contínuo e que tem ajudado os alunos e alunas do curso de turismo da UERJ a terem uma formação mais ampla, não apenas técnica, mas principalmente cidadã, ciente dos seus direitos, dos seus deveres, dos problemas e das outras realidades que os cercam.

Palavras-chave: Município de Teresópolis; Vínculos sociais; Desenvolvimento regional; Cidadania.

Área temática: Direitos humanos

Linha de extensão: Desenvolvimento regional will open new ways, making contacts, involving people and institutions so that they get to know the university and start to relate to it. It is an ongoing effort and it has helped the students of UERJ tourism course to have broader education, not only technical. It has helped develop their citizenship, and helped them become aware of their rights, their duties, problems and other realities that the surround them.

Keywords: Municipality of Teresópolis; Social ties; Regional development; Citizenship

\section{Introdução}

A extensão universitária foi, ao longo do tempo, conforme atesta Serrano', se ressignificando "da extensão nas relações internas com os outros fazeres acadêmicos, e na sua relação com a comunidade em que está inserida". De fato, entende-se que a relação com a comunidade em que está inserida é primordial nos programas de extensão, e é ponto de partida para o projeto construindo vínculos visto que seu principal objetivo é estreitar as relações entre a universidade e o município de Teresópolis considerando que, apesar de estar na cidade desde 2010 ainda há muitos teresopolitanos que desconhecem a presença da Universidade do Estado do Rio de Janeiro (UERJ) na sua cidade.

Por outro lado, o quadro discente, que ainda é, quase em sua totalidade, oriundo da região metropolitana do Estado do Rio de Janeiro, começa a se envolver com o cotidiano da cidade durante o período da faculdade. De algum modo, o projeto promove o encontro e a interação entre alunos e munícipes, exatamente como descrevem Araújo et $\mathrm{al}^{2}$, para quem a experiência da extensão permite ao extensionista não apenas a observação do potencial diálogo entre a comunidade e a universidade, mas também o estreitamento do vínculo entre todos os sujeitos envolvidos no processo em busca de uma sociedade mais justa e igualitária. Conforme Castro $^{3}$, a extensão se apresenta, para a maioria dos membros do projeto, como a possibilidade da universidade interagir com a 
população e de os alunos terem contato com o mundo fora da universidade, e talvez até fora do currículo, ou seja, proporciona experimentação, a aplicação das teorias abordadas em sala de aula e, especialmente, a vivência que possibilita transcender o conteúdo teórico assimilado uma vez que dialoga com a realidade, superando um tecnicismo puro e possibilitando uma formação verdadeiramente superior.

A UERJ está em Teresópolis desde 2010. O acordo para que a universidade se estabelecesse no município previa que a prefeitura municipal de Teresópolis cederia um terreno para que a UERJ construísse o seu campus, mas em um primeiro momento, a prefeitura alugaria um prédio, onde funcionaria inicialmente apenas o curso de turismo, até que o novo campus pudesse ser inaugurado. Questões políticas, tanto na esfera municipal quanto estadual, atrasaram o cumprimento do acordo visto que o município de Teresópolis passou pela tragédia das chuvas que atingiram a região serrana no verão de 2011 e desde então tem convivido com muita instabilidade política, com prefeitos sendo afastados e reassumindo durante a mesma legislatura e, por outro lado, a crise do Estado vem dificultando o financiamento da UERJ não alimentando muitas esperanças de novos investimentos, ainda que acordados anteriormente, por parte da universidade. Desse modo, até o momento a UERJ em Teresópolis disponibiliza apenas o curso de graduação em turismo, e o Departamento de Turismo da UERJ é o único de toda a universidade que funciona em um prédio privado, alugado por uma prefeitura. Tal situação gera, além de problemas muito específicos e incomuns em outros campi, um isolamento do curso em relação aos outros departamentos, professores, alunos e pesquisadores da universidade. Esse é o cenário de onde surgiu o Projeto UERJ Teresópolis Construindo Vínculos, que será abordado na próxima seção.

\section{O Projeto de extensão UERJ Teresópolis Construindo Vínculos}

O projeto teve início em 2014 e, conforme destacado na seção anterior, é ligado ao curso de turismo da universidade, que funciona em um campus avançado, no município de Teresópolis, na região serrana do Estado do Rio de Janeiro. Em 2015, seu segundo ano de execução, o projeto conseguiu uma bolsa de extensão do Departamento de Extensão (DEPEXT) da UERJ, e selecionou uma aluna que desde então tem colaborado sistematicamente no planejamento e na execução de todas as ações do programa. Outros estudantes também colaboram com o programa na condição de voluntários.

Desde o início o Projeto vem se estruturando em torno de três eixos de ação, a saber: ações pedagógicas, voltadas fundamentalmente para a relação entre os graduandos do curso de turismo e estabelecimentos do município de Teresópolis em que se realizam atividades associadas ao turismo; ações sociais, realizadas em benefício de entidades sociais ou filantrópicas do município; e atividades de interação com a comunidade, que são ações que buscam trazer a comunidade pra dentro da UERJ ou divulgar a UERJ em escolas do município e eventos pedagógicos.

A proposta do Construindo Vínculos é não apenas promover a interação da universidade com o município, mas também marcar a presença da universidade em ações que atendem às aspirações apontadas por Carvalho, de que a extensão reforce o caráter 
público da universidade e também a relação orgânica com a comunidade na qual esteja inserida. As seções seguintes abordarão os três eixos de atuação do projeto e, de modo destacado, o projeto do livro infantil.

\section{Ac̣ões Pedagógicas}

O objetivo que orienta a atividade de extensão, de acordo com Carvalho ${ }^{4}$ tem sido o de reforçar o papel social da universidade, ampliando e valorizando as relações com a sociedade e propiciando a troca entre saberes populares e científicos. A universidade, conforme explica Singer ${ }^{5}$, vem sendo afetada pela americanização no plano da cultura, e isso pode ser observado quando percebemos que os critérios de pontuação e avaliação priorizam publicações em inglês, em periódicos editados nos Estados Unidos e na Grã-Bretanha, que demonstram pouco interesse na problemática brasileira. Os programas de extensão, ao fazerem as universidades se voltarem para o seu contexto e a sua comunidade local, amenizam essa questão, pois representam talvez o único estímulo para que as universidades brasileiras lancem um olhar para nossos problemas, nossa cultura e a nossa realidade em um ambiente onde o pragmatismo acadêmico estimula publicar em periódicos internacionais, geralmente com interesses em realidades e contextos muito diferentes daqueles em que vivemos.

Entende-se, então, que os programas de extensão devem nortear-se pelo reforço das relações sociais da universidade com a comunidade local e pelo esforço em contribuir para o desenvolvimento dessa comunidade, ao mesmo tempo em que contribui para a formação cidadã dos seus alunos. As ações do programa UERJ Teresópolis Construindo Vínculos, mesmo aquelas de cunho mais puramente pedagógico, são pensadas sempre com esses princípios.

As ações pedagógicas do programa têm ocorrido semestralmente com pesquisas de campo em estabelecimentos de turismo e hospitalidade da região tais como restaurantes, hotéis, bares etc. Essas pesquisas buscam identificar problemas e propor soluções, e contemplam parte da nota em disciplinas como gestão de recursos humanos e gestão de empreendimentos turísticos. Apesar de o projeto não estar formalmente associado a nenhuma disciplina específica, sempre que possível o projeto dialoga com determinadas disciplinas e seus professores com o intuito de proporcionar interações entre a universidade e o município.

Podemos dizer que as atividades pedagógicas do projeto, além de proporcionar um pouco de aplicação do conteúdo ensinado em sala de aula, permitem divulgar a presença do curso de turismo da universidade no município entre os profissionais da área, promovem o trabalho realizado na UERJ em Teresópolis e criam uma potencial rede de contatos profissionais para os estudantes facilitando a busca por estágios e empregos no futuro.

\section{Ações Sociais}

As ações sociais do projeto de extensão são também pedagógicas porque essas 
ações intensificam aquilo que Schommer ${ }^{6}$ chama de uma experiência existencial para os envolvidos, pois os leva a reflexões profundas sobre suas identidades, propicia novos vínculos e gera impactos em sua formação. Entretanto, para efeito de análise, destaco essas ações de modo especial porque elas promovem a produção de conhecimento de forma mais crítica, como preconizado por Carvalho4, e afirmam com mais veemência a extensão como atividade social conforme colocada pelo referido autor.

As ações sociais do Projeto de Extensão Uerj Teresópolis Construindo Vínculos visam não apenas contribuir com entidades de cunho social ou filantrópico, mas também promover a criação de raízes da universidade no município, fomentar a divulgação da universidade entre os teresopolitanos e, principalmente, proporcionar uma formação cidadã aos graduandos por meio das experiências vividas nessas ações. O projeto já realizou, até o momento, três ações sociais além da elaboração de um livro infantil, que por ter sido uma ação mais abrangente, com desdobramentos em outros eventos e varias etapas de elaboração, será destacado com maior detalhamento em uma seção específica. A intenção é que seja realizada uma ação por semestre para que se consiga sempre bastante engajamento dos alunos. Interrupções no calendário, como a parada para a Copa do Mundo de 2014, e a compensações por períodos de greves anteriores, que geram, por exemplo, interrupções no semestre para as festas de fim de ano, são desafios para a organização e mobilização em todos os semestres.

A primeira ação social foi organizada com o centro acadêmico e ocorreu em maio de 2014, em um abrigo para idosos. Foram vendidas camisas do evento para angariar recursos e, além disso, alunos, professores e funcionários fizeram doações, o que possibilitou a montagem de kits personalizados para cada idoso e a doação de materiais de limpeza, higiene e alimentos ao abrigo. Os kits montados continham produtos de higiene pessoal e uma pequena toalha com o nome do idoso. A preparação desses kits foi realizada em uma oficina preparatória para o evento, o que permitiu a participação inclusive de alunos que não puderam depois comparecer no dia da visita ao asilo. $\mathrm{O}$ evento contou com lanche, bingo, música e até mesmo manicure e maquiagem.

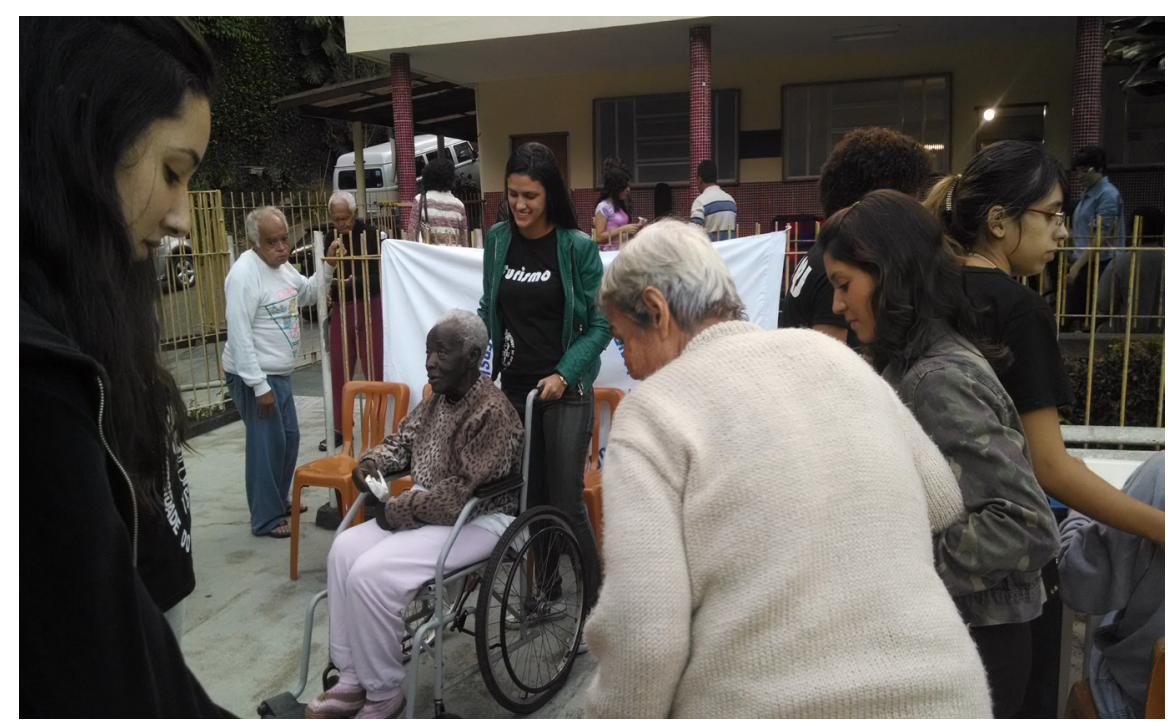



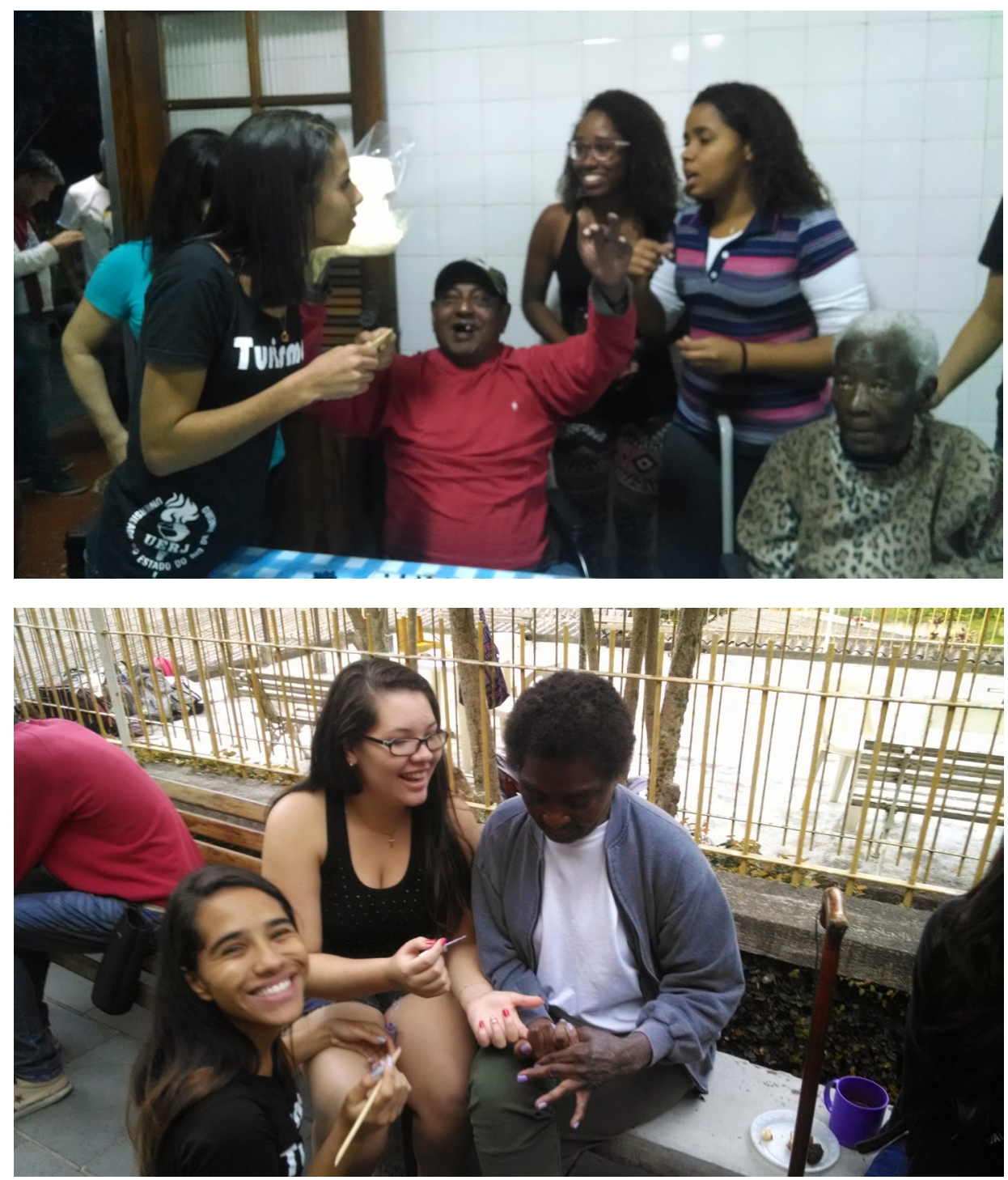

Figura 1 - Ação social na Mansão dos Velhinhos

Figura 2 - Bingo na Mansão dos Velhinhos

Figura 3 - Manicure na Mansão dos Velhinhos

A segunda ação social do programa se deu em dezembro de 2014 no Lar Tia Anastácia, uma casa que acolhe menores carentes no período em que não estão na escola e oferece alimentação, atividades pedagógicas e recreativas, além de oficinas de fotografia, programas de geração de renda etc. Essa ação teve envolvimento maciço do corpo discente, algumas alunas foram fantasiadas de princesas, teve a visita também do Papai Noel, que entregou brinquedo para cada criança. Foi oferecido lanche e também muitas doações de produtos de limpeza, alimentos etc. Para que todas as crianças fossem contempladas o evento ocorreu em dois turnos, com a participação de alguns alunos pela manhã e de outros na parte da tarde, mas a maioria ficou para os dois turnos. Esse evento também foi importante para o surgimento da ideia do livro infantil, que será abordado adiante, pois pela primeira vez tivemos alunas caracterizadas como princesas. 

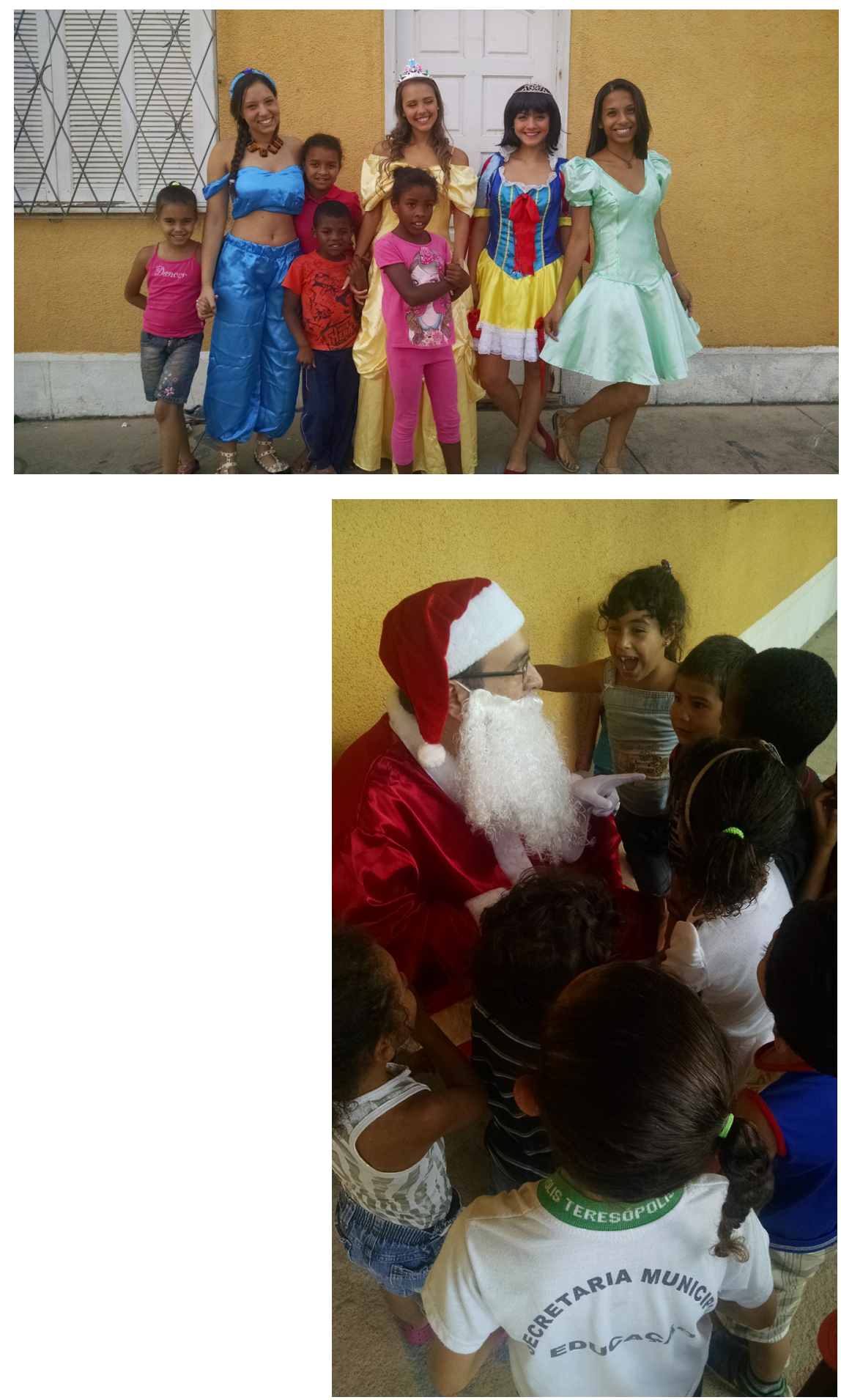

Figura 4 - Princesas no Lar Tia Anastácia Figura 5 - Papai Noel no Lar Tia Anastácia

O terceiro evento do programa se deu em Junho de na Associação Nova Vida, o maior abrigo para menores do município, em setembro de 2015. Considerando que durante a semana as crianças estariam na escola e com obrigações relacionadas a estudo e tarefas escolares, entendemos que teríamos uma participação mais ativa se a ação 
fosse realizada em um final de semana, por esse motivo, o evento foi realizado em um domingo, e assim, apesar de terem sido arrecadadas muitas doações, a participação de alunos no dia do evento foi bem menor, uma vez que a maioria deles não mora no município e volta para casa nos finais de semana. Em uma primeira visita ao local, com alunos ligados ao projeto, com o intuito de conhecer o abrigo e acertar os detalhes da nossa ação, tivemos a recomendação de não publicar fotos das crianças, visto que o abrigo costuma receber, além de crianças abandonadas, outras em situação de risco, vítimas de ameaças, de exploração e de maus tratos, que por questões de segurança, não poderiam ter seu paradeiro divulgado. Para a alegria dos que estiveram nessa primeira visita, no dia da realização do evento algumas crianças que tínhamos conhecido já haviam sido adotadas, e o abrigo já havia acolhido outras crianças. Esse evento contou com a participação de um mágico, que se apresentou voluntariamente, além de jogos, lanche, doações e brinquedos, e a interação dos estudantes presentes com os moradores do abrigo foi bastante intensa.

\section{Atividades de Interação com a Comunidade}

Como dito anteriormente, essas atividades se caracterizam por buscar trazer as pessoas para dentro da UERJ ou levar a UERJ para outros espaços de ensino.

Já em seu ano de estreia, 2014, o projeto propiciou palestra de representantes da associação de moradores de uma comunidade carioca, e em novembro de 2015 recebemos o ex-ministro da igualdade racial, o Sr. Elói Ferreira, que gentilmente nos visitou para falar sobre questões raciais e especialmente sobre o estatuto da igualdade racial, abordando também tópicos sobre os jogos olímpicos de 2016.

Por outro lado, em agosto de 2015 foram realizadas palestras em escolas da região divulgando a UERJ e o curso de turismo. Nessas palestras alunos do projeto também se apresentaram, falaram do curso e da universidade e responderam perguntas dos estudantes dessas escolas.

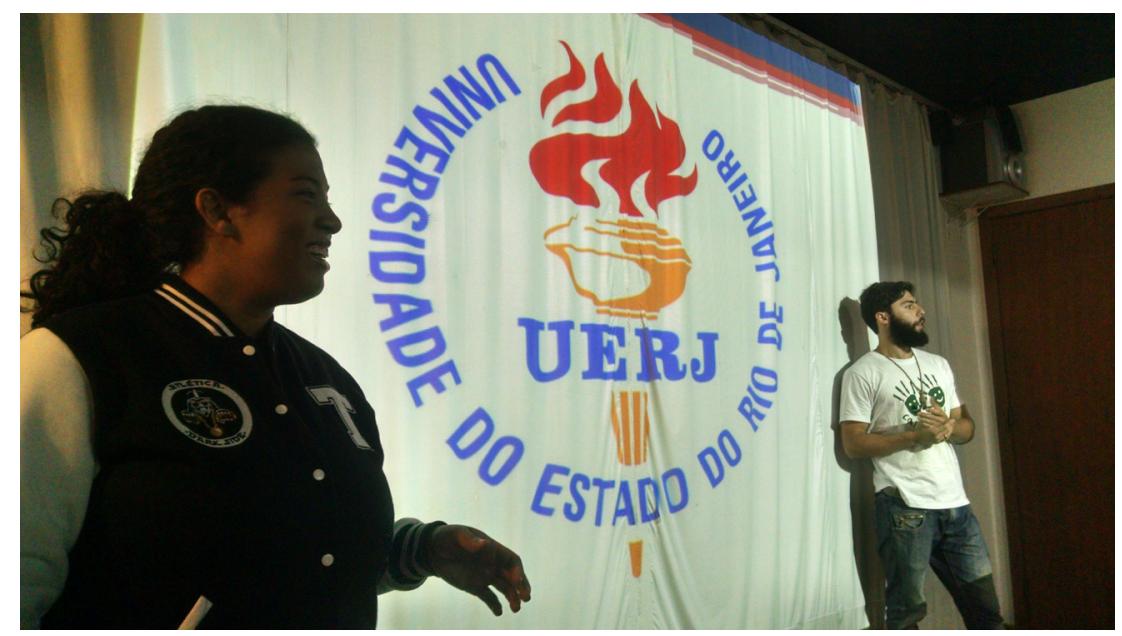

Figura 6 - Palestra sobre a Universidade e o Curso de Turismo em uma escola da região 


\section{O Projeto do livro infantil}

Nessa seção destacamos o Projeto do livro infantil. Conforme dito anteriormente, esse projeto será destacado a parte de outras ações sociais por ter sido bem mais abrangente, com desdobramentos também característicos de nossas ações pedagógicas (como o contato com empresários do ramo turístico) e de nossas ações de interação com a comunidade (como o evento público de lançamento).

Em 2015 surgiu a ideia de fazer, dentro do contexto do projeto, um livro infantil. O desafio era bem grande tendo em vista, entre algumas dificuldades, a total falta de verba. A proposta consistiu em adaptar para livro uma história de princesas, conseguir patrocínio para publicação e reverter toda a renda do livro para uma instituição social da cidade de Teresópolis. A história do livro busca humanizar as figuras de princesas dos contos de fada de forma irreverente e educativa, buscando promover a autoestima das meninas, e a valorização amizade e da diversidade. Como a editora da UERJ não edita livros infantis, buscamos uma editora da cidade que pudesse oferecer um bom preço para publicar e iniciamos a elaboração e a busca por patrocínios.

Decidimos que a renda seria voltada para a Associação de Pais e Amigos do Excepcional (APAE) de Teresópolis, tendo em vista as conhecidas dificuldades que aquele importante instituição vive no município e o relevante trabalho que ela realiza, pois segundo Ferreira et $\mathrm{al}^{7}$ a extensão precisa desenvolver um compromisso de transformar o lugar pela busca da cidadania, e a APAE é nacionalmente referenciada também como uma instituição que luta pelos direitos das pessoas com necessidades especiais, promovendo, assim, o acesso à cidadania para essas pessoas.

Além disso, decidimos que o livro seria ilustrado não por desenhos, como é comum na literatura infantil, e sim por fotos de nossos alunos e alunas caracterizados como os personagens da história, pois já possuíamos um elenco de princesas que haviam participado de nossa ação social no Lar Tia Anastácia, e que prontamente encamparam a ideia. O cenário utilizado para as fotos foi o do hotel Le Canton, que gentilmente permitiu a apoiou a realização das fotos e ainda comprou uma cota de patrocínio, outras duas cotas foram compradas pela MKT Química e pela floricultura Flor do Parque.

Apesar de a história do livro ter sido escrita pelo professor que coordena o projeto, ele é um trabalho de equipe uma vez que foi necessário o envolvimento de varias pessoas para tornar possível sua realização. Além dos discentes que voluntariamente cederam suas imagens para o livro, ajudando inclusive no custeio do aluguel das fantasias, todo o trabalho de produção do livro, tais como maquiagem, fotografia, diagramação etc. foi realizado de forma voluntária por alunos e alunas do curso, com exceção da diagramação, que teve o auxílio da editora, e da revisão técnica do texto, realizada também de forma voluntária, por uma professora do curso. Com os patrocínios arrecadados foram encomendadas 500 unidades (inicialmente a intenção era produzir 1000). Os livros estão em fase de produção e o evento de lançamento, a ser realizado em Teresópolis, será marcado assim que retornarem as aulas do primeiro semestre de 2016, interrompidas pela greve de professores e pelos jogos olímpicos. 


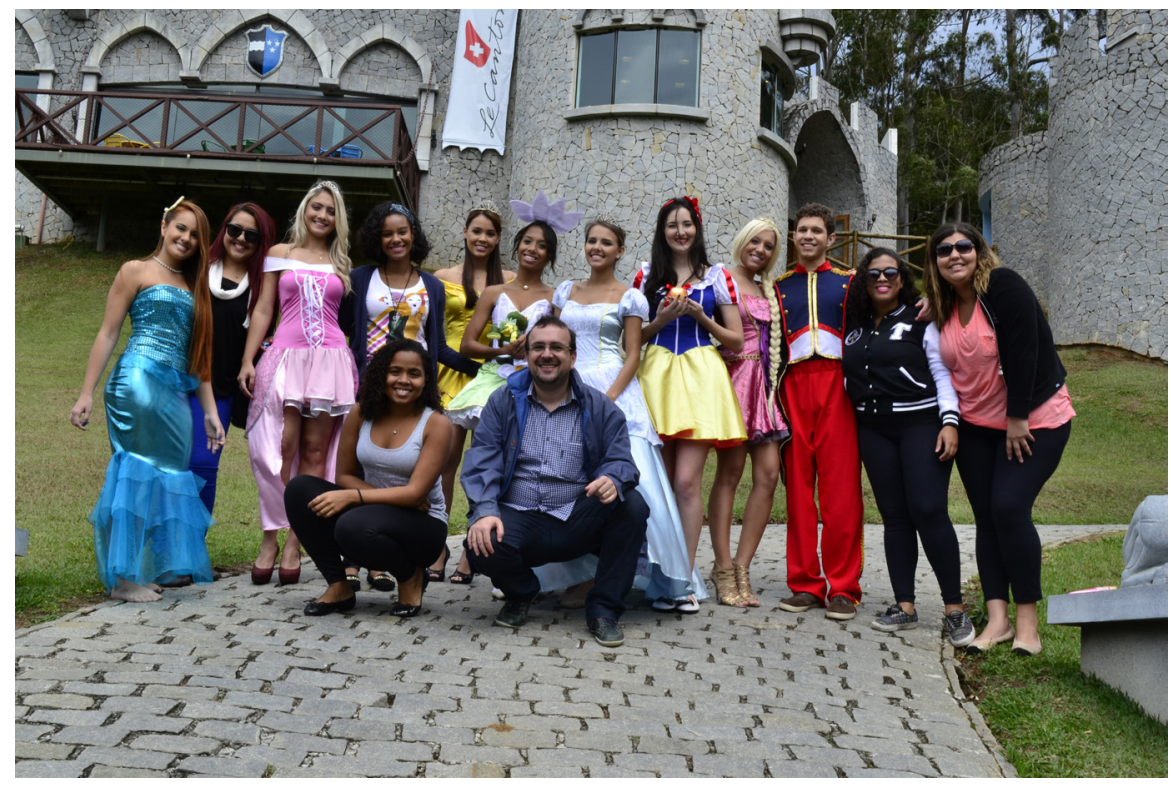

Figura 7 - Equipe do Livro Infantil

Esse livro está sendo um marco para o projeto pela dedicação e engajamento de estudantes, professores, funcionários e até das famílias dos alunos, todos ansiosos para verem o resultado do trabalho. Há um otimismo generalizado de que as 500 unidades serão vendidas em pouco tempo, e que talvez se possa pensar em uma segunda edição para viabilizar projetos de outras instituições.

Freire assevera que a pedagogia quando parte de interesses egoístas dos opressores, ainda que seja um egoísmo camuflado de falsa generosidade, se torna um instrumento de desumanização por manter e encarnar a própria opressão. Nesse sentido, os projetos de extensão, em geral, oferecem ao estudante uma visão de mundo ampliada, e pode se configurar em uma importante ferramenta para uma educação emancipadora, que ultrapasse os limites da visão e dos interesses egoístas do opressor a que se refere Frei$\mathrm{re}^{8}$. No caso específico do livro infantil, por sua natureza lúdica e socialmente engajada, em todas as suas etapas de realização são observados o carinho, a generosidade e o encantamento que ele desperta em muitas pessoas. Desse modo, pode-se afirmar que esse livro vem contribuindo, ainda que de maneira localizada e pontual, para que as pessoas tenham uma visão menos estreita do papel e da importância da universidade, ele merece destaque na trajetória do projeto Construindo Vínculos de promover o espirito humanitário e cidadão da Universidade, cumprindo um papel importante na afirmação da UERJ Teresópolis e de seus propósitos.

\section{Ações Futuras}

O Projeto segue com alguns planos já estabelecidos e outros que podem surgir a partir de ideias dos próprios alunos ou de demandas identificadas no município. Dentre os planos já estabelecidos e que aguardam agendamento após o retorno das aulas estão o evento de lançamento do livro infantil, palestra com a presidente da APAE-Teresópolis, 
ação social na APAE- Teresópolis e a escolha de uma instituição para realizar ação social no ano de 2017.

A previsão é a de que o livro esteja pronto no dia 26 de agosto e as aulas na UERJ serão retomadas no dia 29 de agosto. Sendo assim, o lançamento do livro deve ocorrer em Setembro de 2016. O evento de lançamento deverá ocorrer na Casa de Portugal, em Teresópolis, com cobertura de um jornal local, e com o apoio de dois patrocinadores que deverão arcar com custos de aluguel de fantasias, banner de divulgação do livro, comidas e bebidas do evento etc. O evento terá a participação das princesas, de representantes da APAE-Teresópolis e dos patrocinadores, de professores, alunos e funcionários da UERJ, e será aberto para toda a comunidade de Teresópolis. A intenção é de também realizar um bingo para os que comprarem o livro com brindes oferecidos pelos patrocinadores. A expectativa é de que sejam vendidos ao menos 100 livros no dia do lançamento. Depois do lançamento, os livros poderão ser adquiridos na secretaria da UERJ Teresópolis ou diretamente com o autor e os demais colaboradores do projeto.

A representante da APAE em Teresópolis será convidada para dar uma palestra no primeiro semestre de 2017 falando sobre a sua instituição e o trabalho que ela vem realizando. A palestra também será uma etapa de preparação para a próxima ação social, a ser realizada na APAE-Teresópolis. Depois de realizadas as ações com a APAE-Teresópolis terão início os trabalhos de pesquisa e elaboração da ação social a ser realizada no semestre seguinte.

Estão também nos planos, mas ainda sem data definida, sessões de cinema e debate abertos à comunidade, proporcionando reflexões sobre temas contemporâneos relacionados à economia, política, turismo, administração, educação etc. A intenção é montar uma mesa após cada filme convidando algum professor de outra instituição ou especialistas nos temas abordados nos filmes, incentivando a participação de estudantes e da população em geral buscando, conforme preconizavam Ferreira et al7, dar vez, voz e ação às comunidades. Essas sessões também representarão uma inovação no programa de extensão tendo em vista que, até aqui, as ações extensionistas do programa visavam levar a UERJ para a comunidade teresopolitana, e com essa ação faremos o caminho inverso: traremos a comunidade para dentro da universidade.

\section{Considerações Finais}

A extensão universitária vem adquirindo importância estratégica em um contexto de internacionalização que tende a levar a universidade brasileira a lançar seu olhar para questões de interesse dos países centrais, estimulando as pesquisas nesse sentido e deixando as questões nacionais e regionais em segundo plano. Os programas de extensão acabam cumprindo um papel de fortalecimento das raízes da universidade, não permitindo que ela se distancie dos problemas vividos pelos cidadãos em seu entorno ao mesmo tempo em que mostra sua relevância na vida da comunidade onde está inserida. A defesa de uma universidade publica e gratuita cada vez mais plural e acessível passa pela valorização da extensão universitária que construa vivências e argumentos diferentes do discurso privatista majoritário entre os proprietários dos meios de comu- 
nicação de massa e seus funcionários.

O programa UERJ Teresópolis construindo vínculos busca fortalecer os laços entre a universidade e o município de Teresópolis. Esse processo não é simples tendo em vista que o espaço físico ocupado pela universidade no município é ainda pequeno e provisório, não favorecendo a visibilidade da Universidade e não oferecendo, no momento, condições para a instalação de outros cursos de graduação ou de um curso de pós-graduação, fatores que, aliados à distância dos demais campi da UERJ e de outras universidades públicas, limitam bastante as possibilidades de pesquisa. Além disso, os problemas vividos pela universidade costumam ter maior atenção da mídia e dos olhares dos cidadãos. Assim, é comum que algumas pessoas se deem conta da presença da UERJ no município devido a passeatas de estudantes pressionando pela instalação do campus ou pelas aulas públicas dadas pelos professores em greve em espaços de grande circulação.

Apesar de todas as dificuldades elencadas, o projeto de extensão UERJ Teresópolis construindo vínculos vai encampando a árdua missão de tornar conhecida a presença da universidade no município de maneira positiva, com ações e intervenções visando beneficiar a cidade, suas instituições e seus habitantes, especialmente os menos favorecidos. Aos poucos o programa vai abrindo frentes de trabalho, fazendo contatos, envolvendo pessoas e instituições que passam a conhecer a universidade e a se relacionar com ela. É um esforço contínuo, que tem buscado, humildemente, contribuir com o desenvolvimento econômico, social e humano da cidade e que tem ajudado os alunos e alunas a terem uma formação mais ampla, não apenas técnica, mas principalmente cidadã uma vez que os torna mais ciente dos seus direitos, dos seus deveres e conhecedores dos problemas e das outras realidades que os cercam.

\section{Referências}

1. SERRANO, Rossana Maria Souto Maior. Conceitos de extensão universitária: um diálogo com Paulo Freire. Disponível em: http://www.prac.ufpb.br/copac/extelar/ atividades/discussao/artigos/conceitos_de_extnsao_universitaria.pdf $>$. Acesso em 08 de agosto de 2016.

2. ARAUJO, Eduarda Pontes dos Santos; CRUZ, Pedro José Santos Carneiro; ALENCAR, Islany Costa, CARNEIRO, Daniela Gomes de Brito. Educação Popular no processo de integração Ensino - Serviço e Comunidade: Reflexões com base em Experiências na Extensão. Revista APS. Juiz de Fora: UFJF. v. 18, n. 4, p. 447-455, out./dez. 2015.

3. CASTRO, Luciana Maria Cerqueira. A universidade, a extensão universitária e a produção de conhecimentos emancipadores. In: 27̣a Reunião Anual da ANPED. Anais da 27a Reunião Anual da ANPED. Caxambu, MG, 2004. Disponível em: http://www. anped.org.br/reunioes/27/ Acesso em: 05 ago. 2016.

4. CARVALHO, Sônia Marise Sales. Reflexões sobre a extensão na universidade pública brasileira. Revista ParticipAção. Brasília. 2009; (16): 12-20.

5. SINGER, Paul. A universidade no olho do furacão. Dossiê Educação. Estudos Avan- 
çados, São Paulo, v. 15, n. 142, p. 305-316, maio/ago. 2001.

6. SCHOMMER, Paula Chies; FRANÇA FILHO, Genauto Carvalho de. A metodologia da residência social e a aprendizagem em comunidades de prática. NAU - Revista Eletrônica da Residência Social do CIAGS/UFBA. Salvador: CIAGS/UFBA. v. 1, n. 1, p. 203-226, jun./nov. 2010.

7. FERREIRA, Marcia Regina; SILVA, Francielle da SILVA; ZANATTA, Renan A. Ferreira. Da Dialogicidade entre Universidade e Comunidade: Um estudo de caso da Extensão Universitária a partir do exercício da Democracia Dialógica na Pesquisa-Ação. Cadernos de Gestão Social. Bahia; UFBA. v.13, n.1, p.56-68, jan./jul. 2012.

8.FREIRE, Paulo. Pedagogia do Oprimido. Rio de Janeiro: Paz e Terra, 2005. 48 reimpressão, 